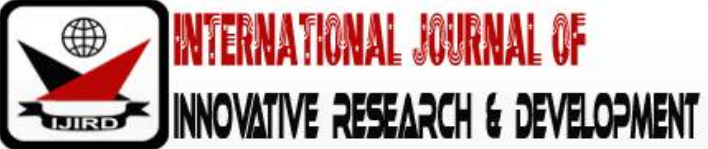

ISSN 2278 - 0211 (Online)

\section{The Influence of Organisational Factors on Employee Performance}

\author{
Seita Almandeel \\ Assistance professor, Department of Business Administration, \\ King Abdulaziz University, Saudi Arabia \\ Asma M. Alshahrani \\ Post Graduate Researcher, Department of Business Administration, \\ King Abdulaziz University, Saudi Arabia
}

\begin{abstract}
:
The purpose of this paper is to investigate the influence of organisational factors on the in the performance of administrative employees at KAU. The data required has been obtained using the survey questionnaire method, which was administered to a random sample of the administrators at KAU. Around (475) responses were collected from the participants, but since the researcher was only interested in employees who had received training, (109) responses were excluded. As a result, the valid responses equalled (366). SPSS was used for data entry treatment and analysis. The study produced various findings, the most important ones are listed below; training has a significant impact on employee skills, and helps to improve employee performance; there are positive indications supporting the notion that workload influences the employees' performance; effective leadership has a positive effect on employees' performance; transformative leadership has an impact on employees; there are statistically significant relationships between employee performance, and the three main organisational factors (effective training and development, workload, and transformation leadership); there is a statistically significant difference between employees towards the influence of effective training and development on their performance, and positive to the side of male participants. Considering the results of the study, it is recommended that for the organisation to achieve advantages in sustainability it should concentrate on training employees to improve their skills, as well as schedule training programmes and create schemes to incentivise supervisors.
\end{abstract}

Keywords: Performance, training, workload, leadership, transformation leadership, organisational factors

\section{Introduction}

Nowadays, organisations are forced to compete and to act professionally in hard times - they must create competitive advantage by hiring employees who have the capability to do it. One of the most important dependent variables that can affect the organisation's success is employee performance, which has been studied for decades (Wall et al., 2004). Employees are an instrument to achieved improved performance in the organisation (Armstrong, 2009). In any organisation, it can be considered that employees are an important asset for optimal and effective performance. An organisation can achieve infinite output, effectiveness and efficiency if the full potential of their human resources is unlocked. Truong (2012) explained how the differences between employees working levels and methods can be used to effectively attain maximum productivity. Prince Mohammed Bin Salman's Saudi Vision (Gazette, 2016), he illustrates that the Saudi country will no longer solely depend on oil and other natural resources to satisfy their energy needs. The Saudi Vision demonstrates the determination of Saudi nations to become global investment powerhouses, and states that they hold strong investment capabilities, which will be harnessed to stimulate the economy and diversify their revenue streams. The 2030 Vision is orientated at minimising governmental dependency on oil, so other sectors, such as services and industry, will be encouraged to follow suit and improve their performance. National human capital is one of the main agendas of the 2030 vision - the Saudi government is trying to build national competencies to decrease the dependency on foreign employees. Accordingly, managers must be able to investigate whether or not their employees are performing their work effectively and efficiently, based on the requirement of improvement (Robbins and Coulter, 2009). There are many factors that can affect employee performance, this study intends to illustrate the impact of organisational factors on the employee performance at King Abdul-Aziz University (KAU). The dependent variables are the organizational factors of training, leadership and workload, while employee performance is considered the independent variable of this study.

Any business or organisation in the world, whether private or public, aspires to develop, expand and survive indefinitely. However, the business environment is unpredictable and companies regularly face intense competition. Progress is inevitable, as is improvement, and both require continuous change, whether in the products provided, in production methods, or employee performance. Khan (2016) reported that having a positive work environment is important for the mental, physical, and emotional health of employees, and also for the quality of service and product in 
any organisation, as feeling happy and comfortable at work leads to greater loyalty and productivity. Organisations operating in the development of a globalised and competitive era seek to find employees who are high achievers in their performance. Performance in any organisation is continuously measured and monitored through well-known and defined processes that involve the testing of many variables. Organisations cannot achieve their desired goals without experienced and qualified employees as one of those variables. The purpose of this study is to identify the relationship between employee performance and the key organisational factors of training, workload and leadership. These factors have chosen for this study as there has been a lack of research completed in this area in the context of Saudi educational institutions. Despite the separate and plentiful research on these factors individually, there is no research that brings them together in an attempt to improve employee performance. Kagaari et al. (2013) explained that public universities in Uganda have faced significant challenges regarding employee performance during recent years, which led to these institutions finding themselves in an increasingly competitive environment where there was a smaller number of students available. This study aims to examine the effects of training, workload and leadership management, with emphasis on transactional leadership, on the performance of the administrative employees at King Abdul Aziz University (KAU).

This study offers several important contributions. Theoretically, it offers a thorough view of the impact of several organisational factors (workload, training, and effective leadership), on employee performance in both public or private Saudi organisations, particularly educational institutions. Regarding the effectiveness of leadership, the study will aid in understanding the impact of the application of transformational leadership practices on enhancing employee performance in that sector. Additionally, with regards to training and development, it will investigate which is the most beneficial type of training, either internal or external, to achieve the best employee performance. Concerning workload, the study will help to identify the level of workload that will positively affect the performance of employees. Practically, this study will assist organisations in Saudi market with the development of human resources that will improve performance, and thus, the success of the organisation. This will allow organisations to achieve the expected 2030 Saudi Vision. The results of this study will also aid leaders and managers in improving the performance of their employee my effectively controlling the three organisational factors mentioned earlier - the successful completion of which will help them to achieve organisational success.

\section{Theoretical Background}

Organisations usually aim to improve the job performance of their employees, which helps them survive in a highly competitive environment (Anyango, 2015). According to Tolulope (2016), employee performance depends on people executing their job duties and responsibilities well. Efficient employee performance is indispensable for the success of an organisation; this is because they depend on employee creativity, innovation, and commitment in order to achieve their organisational objectives (Ramlall, 2008). This means that the contribution of each individual is vital to the implementation of organisational goals. The concepts of employee performance have been considered diverse by many researchers, and management scientists have, thus far, been unable to reach a unified conclusion, each having their own perspective and interpretation. One such viewpoint defined employee performance as the successful completion of individual tasks set by an organisation, according to an established criterion, besides an efficient utilisation of resources in a changing environment (Zafar et al., 2015). Pattanayak (2005), on the other hand, explained employee performance as a behaviour resultant of a task which can be evaluated and observed, in other words, the contribution of an individual towards the implementation of organisational goals. The performance of an employee is usually measured against performance standards set by the organisation (Kenney \& Reid, 1986). McEvoy (1990) discovered that the phenomenon of performance appraisal was a fundamental problem faced by public organisations. He also stated that measuring the actual performance of an individual is the most challenging aspect of an appraisal process aimed at improving employee performance. Chandra \& Priyono (2015) added that a performance appraisal is a means of measuring the contributions of an employee to their role in an organization. Rusu et al.'s (2016) study about employee performance appraisal revealed the existence of a conceptual framework which emphasized the considerable importance of a customised appraisal process. To enhance such a performance appraisal, they dictated that it must be individually tailored to each employee. At the same time, they set flexible appraisal systems which aimed to improve both individual and overall organisational performance. There are many measures that must be taken into consideration when measuring performance, such as efficiency, quality, effectiveness, profitability and productivity (Orlin \& Ahuja 1992). Chanana and Gupta (2016) stated that an excellent quality of work life in the working environment would have a positive influence on employee performance. The working environment has long indicated an interconnected relationship between a worker and his environment, which may be broken down into various dimensions, such as technical, economic and social, which are viewed and designed in work (Bushiri, 2014). Accordingly, Purbasari \& Septian (2017) advocated a study of the factors influencing employee performance in the production departments of food manufacturers in Indonesia, which was concerned with the maintenance of performance within the organisation. The study sampled 127 production employees, with the primary source of data coming from questionnaires. The findings show that compensation and positive work environment can impact employee performance. Work environment and compensation will be considered in this study in order to develop employee performance which is influenced by them. Employee performance is a critical factor that contributes directly to the performance of the organisation. Organisations today, with rising competition in the business arena, are keen to enhance employee performance to improve their profitability and market reach. Employee performance in any job is gauged by various criteria, depending on the job requirement. Many factors have been highlighted as affecting employee performance, and clarifying the relationship between them seeks to improve employee performance. This study will discuss how employee performance can be affected by organizational factors. 


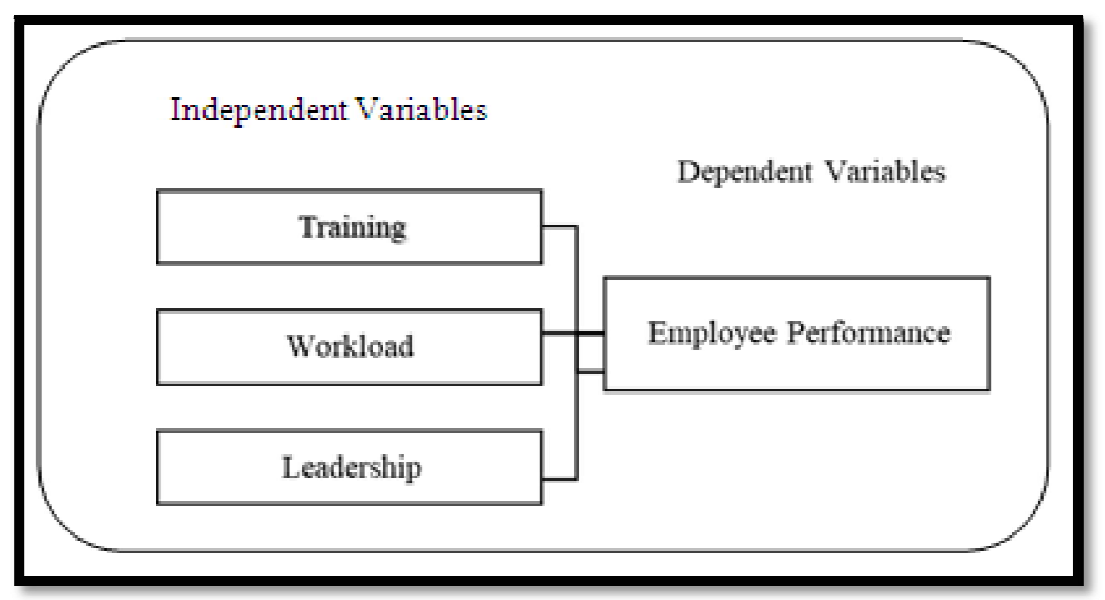

Figure 1: Conceptual Framework

\subsection{Training and Employee Performance}

In the development of organisations, training plays a significant role in improving performance and increasing productivity. Training employees will help to place the organisation in the best situation to overcome competition and remain at a higher rank. Giving due attention to the skills and motivation of employees is critical to the success of any organisation (Jon and Randy, 2009). Many organisations deal with employee performance as a main factor of their success (Mathis and Jackson, 2004). This means that organisations that train their employees have a significant continuance of development compared to others. Training mostly aims to raise the professional knowledge needed to build a successful organisation, which includes the development of all behavioural aspects of the employees with their work teams within that organisation (Bu Sunaina et al., 2003). The concept of training is defined by many scholars, with each of them exploring it from their own perspective and point of view. Training is described by Eze (2005) as the time spent by an individual gaining the knowledge and skills to successfully complete tasks that help an organisation maintain its positions. Gordon (1992) said that training is one of the planned organisational activities which enhance qualifications, competency, and knowledge levels and that lead employees to perform their jobs efficiently. This study adopts the definition of training as "the organized process that helps employees to gain new skills, to change their behaviour and to improve their performance." Training activities can have some positive effects on either individuals or groups and facilitate valuable outcomes such as motivation, empowerment, and attitudes (Aguinis \& Kraiger, 2009). For an active programme of training and development to be effective, Madhruma and Sheetal (2009) explained that the significant cause of the training must be apparent to the employee through the trainee, by which he must clarify the reasons behind this training and the offer a proper opportunity to undertake it. In other words, employees must have a clear perception of the ways to implement their training to acquire the necessary behaviour for good work performance. Effective training programmes enhance the competencies of employees. Likewise, they improve the current performance of employees and increases future skills and knowledge, which in turn progresses organisational performance (Wright \& Geroy, 2001). Atan at el, (2015) conducted a study into the impact of training on employees' job performance in small and medium enterprises in Malaysia. 85 employees participated by responding to a questionnaire, the results of which indicated a positive relationship between effective training and employee performance. Milkovic \& Bordereau (2003) added that for training programmes to prove advantageous, they must be designed in a manner that fits the needs of the employees. Specialists in human resources divided the method of training into on-the-job and off-the-job training (Goldstein, 1974). According to Campbell et al. (1988), 'on-the-job training' occurs in the organisation's environment and is focused on real task for employees, and is often provided by other employees who have more experience, or is presented under the direct supervisor of those employees. It may appear as a form of job rotation, job enlargement and job instruction training. 'Offthe-job training' includes training programmes which are held outside the workplace. These may be including of audiovisual presentations, simulations, and case studies (Carvell, 1970). In the end, the decision to focus on one type of training and neglect the other may be dictated by the type of training that is most appropriate for the employee. However, managers must have knowledge of the different types of training, as this will help to expand their ability to select an appropriate model for their employees to improve performance. The current study assumes that on-the-job-training that is organised at the trainee's place of work will be the best choice for the organisation. This assumption is supported by Ognjenović (2015) who clarified that only on-the-job training and specific training could provide certain benefits to the organisation.

Training is one of many methods that attempt to overcome deficiencies in human performance within organisations. It has the ability to enhance the skills of employees as well as their competencies and abilities, which may lead to organisational success. Technological and organisational developments have increased the importance of continuous investment in the development of employee's skills and abilities, which is the foundation of organisational success (Beardwell et al., 2004). Organisational success depends on the investment in continuous training, which will carry an organisation from an average to a high-level business (Church et al., 2015). Anitha \& Kumar (2016) studied the impact of training on employee performance in the insurance sector. The study aimed to uncover the impact of training on employee performance, as well as the factors that affect the productivity of those trained. The results showed a noticeable improvement on the level of employee performance and productivity. The study defined the standard factors which 
determine the growth of employee performance after training: education level, employee category and work experiences. Training fulfils a significant part of the process required to achieve a system of continual development of employees. Thus, if the organisation has the right workforce, who possesses the proper skills to do their job correctly, then this will lead to an improvement in employee job performance. In this study, the researcher seeks to explore the relationship between effective training programmes and the improvement of employee performance. This could guide other studies to the existence of such connectivity, and encourage its improvement in various methods. Based on the previous studies, the following hypothesis of this part was formulated:

- H1: There is a relationship between effective training and employee performance.

\subsection{Workload and Employee Performance}

Workload, work-life balance and stress are the most widespread problems faced by organisations. Each person has experienced some degree of stress variables, both in their personal life and at work, which has an effect on their health and performance. Workload is one of the main factors having an influence on employee productivity and efficiency. Dayby-day, workload and stress issues are rising, which necessitates the conducting of studies to solve such problems (Shah et al., 2011). Leedal \& Smith (2005) conceptually defined workload as a multi-dimensional construct influenced by physical, cognitive, and psychological factors. It refers to the equilibrium between the challenge of a given task and the person's response to it. In addition, workload refers to the amount of work a person is responsible for completing (Cobuild, 1999). Furthermore, Carlson (2003) defined workload as the amount of activities that have to be completed by an individual, or group of people, over a specific amount of time, under a normal status. The researcher has clarified workload in this study as the amount of work which must completed by a person or a group, and that is to be done in a certain period. Workload has an association with physical and mental componence tasks. Workload or mental demand indicates the attentional requirements of a task, and the capacity of a person is the quantity of attention resources obtainable for task performance. For most tasks, there is an associated physical and a mental component of workload (Emery, 2012). Determining and measuring the development of a workload presents a challenge, because the scientific effort that is associated with the performance of tasks needs a physiological cost (Matthews et al., 2008). Another factor that impacts task performance is workload history, which means the activity that was completed by the individual immediately before the critical work period. According to Cox-Fuenzalida (2007), workload history has an implication for performance, especially when there is diversity or a shift in the workload; in such a situation, performance might suffer. A study of the subject "A Comparison of Sudden Increases and Decreases on Performance", which was examined by Cox-Fuenzalida et al., (2006), unexpected changes in workload level were designed and executed with the objective of being able to trigger a direct comparison of performance following a sudden rise or decrease in workload. The results of this study showed that performance was significantly diminished in both conditions. The findings indicated that either a sudden reduction (High to Medium) or rise (Low to Medium) in workload could result in declined performance. Work overload can be classified into quantitative and qualitative overload. Quantitative overload is shown as "having too much to do", whereas qualitative work overload is defined as a task being "too difficult to do". The condition commonly referred to as work overload is when the employees feel they have too much work to do, too large a variety of things to do, or the time available was not enough to complete the job (Carlson, 2003). Finally, workload can be adjusted by the manager or supervisor to bring out the best performance from the employees. This task is difficult, so the assignation of workload might be reviewed by the senior or head managers to determine the level of workload and ensure a proper balance. This study will examine the role of workload in improving employee performance in KAU. This will help to determine the optimum workload, and thus control its rise or decline thus contributing effectively to achieving the objective of this study. Based on above studies, the following hypothesis was formulated as:

- H2: There is a relationship between workload and employee performance.

\subsection{Leadership and Employee Performance}

The presence of a person as an individual has been associated with the developments and changes made by individuals and groups throughout human history. Leadership is an essential component of management when it is considered as a function (Shafie et al., 2013). The quality of leadership presented by managers has been reflected in the performance of employees, which in turn affects the overall performance of the organisation (Basri et al., 2017). Organisations have broadened globally and face challenges in meeting their objectives to be more successful than others. Given this point, leaders play a significant role in the implementation of these goals and enhance employee performance by satisfying them in their jobs (Paracha et al., 2012). Successful leaders motivate employees by encouraging them to create a less morbid and more enriching work environment, as well as contribute ideas in an attempt to enhance performance (Khaliq, 2001). Leadership is defined as the possibility of persuading others to search for specific objectives. It has been considered as the human factor that collects a group together to do two things - directing them toward goals and improving their performance (Adair, 2002). Also, it is defined by Robbin (2006) as the capability to have an effect on a group to reach a goal. Effective leadership has been viewed as a vigorous source of management development and sustained competitive advantage, for the improvement of the performance of both the organisation and employees (Rowe, 2001). Effective leadership refers to the way in which leaders positively motivate followers to strengthen themselves while achieving the organisational objective (Conchie, 2013). When organisations need to meet their goals, they must provide the effective leadership necessary to be a successful organisation (Shafie et al., 2013). Aggarwal and Krishnan (2013) indicated that effective leaders usually use their influence on followers and organisations in order to improve them. Effective leadership has a presence in the organisation when the group members are motivated, capable and highly skilled enough to work on their own (Cherry, 2012). On the other hand, if the group members lack the experience or 
knowledge that is needed to complete tasks and make decisions, effective leadership is not sufficient (Judge\& Piccolo, 2004). Psychogios and Garev (2012) have demonstrated this in a study of leadership in small and medium-sized enterprises (SMEs). They conducted interviews with 32 employees in middle management, then carried out a document review to collect data. From regulation and procedure documents, as well as the responses of managers, it was indicated that a lack of role clarity, the absence of a vision, and uncertainty had had an undesirable influence on employee performance. It was possible to glean from these important results that the relationship between employees and leaders has positive effects on work outcomes, behaviours, and employee attitudes when clarity exists. All leaders must have an individual follower, but to be an active leader they need an enthusiastic follower. Effective followers must have the essential traits of leadership to be relevant (Jowah, 2013). The study seeks to affect the leadership role, to enhance the role of leaders on their employees and arrive at the best practice and performance from there. This study will focus on transformational leadership theory, because much of the evidence has proved that it has more beneficial results on the employees than other approaches (Mohiuddin, 2017). Transformational leadership, in its effective role, has improved employee performance. According to Bass (1985), transformational leadership helps individuals and organisations motivate and transform beyond the expectations of their performance by moral values. Bass \& Riggio (2006) add that the transformational leader can transform the thinking of followers and achieve the organisational vision as if it was their own, meaning employees are able to pursue collective goals and overcome personal interests. The study conducted by Qazi et al., (2014) on the telecom and banking sector shows that each different style of leadership practiced through management will affect employee performance. The study was based on the distribution of a questionnaire to collect and then analyse information -they received 77 completed questionnaire papers out of the 100 distributed. They found that there was a significantly association between the practice of leadership style and employee performance, in particular the transformational leadership style. As such, the implementation of transformational leadership theory can help the employee to improve his performance as it requires the development of employee knowledge (Yukl, 2006). Howell and Merenda (1999) added that transformational leadership had played an imperative role in fulfilling organisational objectives and improving employee performance. Finally, leadership has an effective role in employee performance. With the large volume of differing leadership styles and theories, this research focusses on transformational leadership, as previous studies have indicated its positive impact on employee performance, which the purpose of the current study. Based on previous literature, the hypothesis was formulated as:

- H3: There is a relationship between transformational leadership and employee performance.

\section{Methodology}

The descriptive analytical approach is used to carry out this study, which is an investigation that describes and analyses the data. It is usually used in the research of social and human sciences. According to Brown and Rodgers (2002), descriptive research is defined as "research that describes a group of characteristics or behaviours in numerical terms". They emphasize that descriptive statistics are used to analyse descriptive research data. To collect data, a questionnaire is used as an instrument for gathering information from the sample, i.e., administrative employees.

This study used in-depth method, well-structured questionnaires in order to extract the required information to achieve the research objectives. Questions in the training part of the questionnaire were quoted from Nassazi's study Effects of training on Employee Performance". The performance and transformational leadership parts were quoted from Anyango's study " Effects of Leadership Styles on Employee Performance at Boa Kenya Limited, 2015". In addition, the effective leadership questionnaire quotes a study by Bass \& Avolio (1995), using an instrument called 'Leader and Rater Form' and Scoring Guide. Finally, part of the workload questionnaire was quoted from a study titled "Examining the relationships between Canadian public health nurses' job satisfaction and their autonomy, control-over-practice, and workload" by Graham.

\section{Results}

In this study, the research population includes all the administrative employees at King Abdulaziz University in Jeddah, both the male and female sections. The researcher distributed the questionnaire and was able to gain 475 responses. As the researcher is interested in studying the influence of training on the performance of administrative employees, only the participants who had participated in training since they were employed at the University were selected. This meant that 109 participants were omitted and the administrative staff who had received training amounted to 366. Participant distribution according to gender showed that the male and females are equally represented. Participant distribution according to age revealed the plurality of participants as follows; $44.3 \%$, were in the age class 31 to 40 years old, $26.2 \%$ were in the age class 41 to 50 years old, $13.1 \%$ of the participants were less than 30 years old, $12.8 \%$ were in the age class 51 to 60 years old, and only $3.6 \%$ of the participants were the age class of more than 61 years old. Therefore, most participants of the current study could be considered 'youthful', which indicated that the majority need training programmes intended to enhance their performance. With regards to participant distribution according to their tenure at KAU, it was noticed that the majority ( $71.9 \%$ ) had been employed for more than 3 years, while $20.4 \%$ were employed for 1 to 3 years and $7.7 \%$ had been employed for less than 1 year. Thus, it can be seen that most participants had been employed for more than 3 years. The participant distribution according to job status, in terms of full time or part time employment, showed that the majority of administrative employees (85.8\%) were full time employees, while only $14.2 \%$ worked parttime. 
4.1. The Questionnaire Validity and Reliability

The below table attempts to find the degree of association between each item and the dimension to which it related.

\begin{tabular}{|c|c|c|c|c|c|c|c|c|}
\hline \multicolumn{9}{|c|}{ Dimensions } \\
\hline \multicolumn{2}{|c|}{$\begin{array}{l}\text { Training and } \\
\text { development }\end{array}$} & \multicolumn{2}{|c|}{ Workload } & \multicolumn{3}{|c|}{ Employee performance } & \multicolumn{2}{|c|}{ Effective leadership } \\
\hline $\begin{array}{l}\text { Item } \\
\text { No. }\end{array}$ & $\begin{array}{c}\text { Correlation } \\
\text { coefficient }\end{array}$ & $\begin{array}{l}\text { Item } \\
\text { No. }\end{array}$ & $\begin{array}{c}\text { Correlation } \\
\text { coefficient }\end{array}$ & $\begin{array}{l}\text { Item } \\
\text { No. }\end{array}$ & & rrelation coefficient & $\begin{array}{l}\text { Item } \\
\text { No. }\end{array}$ & $\begin{array}{c}\text { Correlation } \\
\text { coefficient }\end{array}$ \\
\hline 1 & $0.414^{* *}$ & 7 & $0.684^{* *}$ & 12 & & $0.736^{* *}$ & 16 & $0.803^{* *}$ \\
\hline 2 & $0.494^{* *}$ & 8 & $0.722^{* *}$ & 13 & & $0.765^{* *}$ & 17 & $0.847 * *$ \\
\hline 3 & $0.691^{\text {** }}$ & 9 & 0.596 ** & 14 & & $0.638^{* *}$ & 18 & $0.847^{* *}$ \\
\hline 4 & $0.728^{* *}$ & 10 & $0.409 * *$ & 15 & & $0.785^{\text {** }}$ & 19 & $0.795^{* *}$ \\
\hline 5 & $0.705^{* *}$ & 11 & $0.627 * *$ & & & & & \\
\hline 6 & $0.695^{* *}$ & & & & & & & \\
\hline \multicolumn{9}{|c|}{ Transformational leadership } \\
\hline $\begin{array}{l}\text { Item } \\
\text { No. }\end{array}$ & $\begin{array}{l}\text { Correlation } \\
\text { coefficient }\end{array}$ & $\begin{array}{r}\text { Ite } \\
\mathrm{N}\end{array}$ & $\begin{array}{l}\text { Correlat } \\
\text { coefficie }\end{array}$ & & & $\begin{array}{c}\text { Correlation } \\
\text { coefficient }\end{array}$ & & \\
\hline 20 & $0.757 * *$ & 2 & $0.781^{*}$ & & & $0.761^{* *}$ & & \\
\hline 21 & $0.768^{* *}$ & 2 & $0.806^{*}$ & & & $0.761^{* *}$ & & \\
\hline 22 & $0.787^{* *}$ & 2 & $0.798^{*}$ & & & $0.826^{* *}$ & & \\
\hline 23 & $0.741^{* *}$ & 2 & $0.814^{*}$ & & & $0.677^{* *}$ & & \\
\hline
\end{tabular}

Table 1: The Results of the Persons' Correlation Coefficient

The results demonstrate that all items are statistically correlated with the dimension to which they related - it was noticed that the values extended between 0.414-0.847, and all correlation coefficients are statistically significant. This confirmed that all items included in the survey questionnaire method achieved the purpose of measurement, which means that the method is efficient enough to collect the required information.

\subsection{Testing Hypothesis}

- H1: There is a relationship between effective training and employee performance.

\begin{tabular}{|c|c|c|}
\hline Variables & \multicolumn{2}{|c|}{ Effective Training } \\
\hline Employee performance & Person's correlation & P-value \\
\cline { 2 - 3 } & $0.332^{* *}$ & 0.00 \\
\hline
\end{tabular}

Table 2: The correlative relationship between effective training and employee performance **Indicated that the correlation coefficient is significant at the (0.01) level

The results in Table (2) show the correlation coefficient between the two variables, effective training as an independent variable and employee performance as a dependent variable, reaching 0.332 , which is statistically significant at the 0.01 level. This result revealed that there is a significant correlative relationship between effective training and employee performance. This means that if training programmes are well designed to satisfy employee needs regarding their skills to do their job, their performance will improve.

- H2: There is a relationship between workload and employee performance.

The results of testing this research hypothesis were presented as shown in the table below:

\begin{tabular}{|c|c|c|}
\hline Variables & \multicolumn{2}{|c|}{ Workload } \\
\hline \multirow{2}{*}{ Employee performance } & Person's correlation & P-value \\
\cline { 2 - 3 } & $0.429^{* *}$ & 0.00 \\
\hline
\end{tabular}

Table 3: Showed the correlation between workload and employees' performance

**Indicated That the Correlation Coefficient Is Significant at the (0.01) Level

The results in Table (3) revealed that the correlation coefficient between the two variables, workload as an independent variable, and employee performance as a dependent variable, reached 0.429 , which is statistically significant at the 0.01 level. This result confirmed that there is a significant positive correlative relationship between workload and employee performance. This means that the employees at KAU were working under a heavy workload, being required to accomplish their job tasks, whether that meant they came to work early or stayed late.

- H3: There is a relationship between transformational leadership and employee performance. 


\begin{tabular}{|c|c|c|}
\hline Variables & \multicolumn{2}{c|}{ Transformational Leadership Perception } \\
\hline \multirow{2}{*}{ Employee performance } & Person's correlation & P-value \\
\cline { 2 - 3 } & $0.284^{* *}$ & 0.00 \\
\hline
\end{tabular}

Table 4: Shows the Correlative Relationship between Transformational

Leadership and Employee Performance

**Indicated That the Correlation Coefficient Is Significant at the (0.01) Level

The results in Table (4) reveal the correlation coefficient between the two variables, transformational leadership as an independent variable and employee performance as a dependent variable, reached 0.284 , which is statistically significant at the 0.01 level. This result confirmed that there is a significant positive correlation between transformational leadership and employee performance at KAU. This means that transformational leadership is practiced in the university by the supervisors, which encourages employees to carry out their work efficiently.

\section{Discussions}

With regards to the impact of training and development on the performance of administrative staff at KAU, the study showed that training has a significant impact on their skills and helps to improve their performance. The study found that there is a significant relationship between training and development and administrative employee performance at KAU. In addition to that, the study found that training and development has a positive and significant influence on employee performance. The above results of the current study concurred with the findings of the study conducted by Bayraktaroglu \& Cickusic (2013), in which they concluded that training and development are the primary keys to the success of employees and organisations. Furthermore, there was a significant impact on employee performance when they realised that training programmes afforded them better knowledge and improved their skills.

In addition, our current study found common ground with a study conducted by Ibrahim et al., (2017), in which they aimed to achieve the objective of training and development on employee's soft skills, which has a significant and continuous impact on improving employee performance. The study showed that when employees or trainees obtain the necessary soft skill elements it will result in increased work performance. Furthermore, the current study, with regard to the impact of training and development on employee performance and productivity, also agreed with the findings of a study conducted by Anitha \& Kumar (2016), which aimed to find out the impact of training on employee performance and the factors that affect the productivity of trainees. The results showed that there is a noticeable improvement in the performance level of employees and their productivity. Furthermore, the result of the current study also agreed with the findings of a study conducted by Atan et al., (2015), in which a positive relationship was found between effective training and employee performance. Furthermore, the results of the current study, derived from regression analysis, are in line with the findings of a study conducted by Bayraktaroglu \& Cickusic (2013), which discovered that there was a significant impact on employee performance when it was realised that training programmes afforded them better knowledge and improved their skills.

With regards to the impact of workload on the performance of the administrative employees at KAU, the study showed that there are various indications that workload has an influence on employee performance. The most important of these indications include the fact that most employees confirmed that they have too much to do, and in order to do everything well, because of workload, they often have to arrive early or stay late to accomplish their work, and others showed they often have too much work for one person to do. Based on that, the results of the correlative relationship between workload and administrative staff performance revealed that there is a positive connection between the two variables. Additionally, the regression analysis found that workload has an influence on the employee performance.

The above results of the current study, in which we argued the impact of workload on employee performance, showed that there are major indications that workload has an impact on employee performance, including having too much work to do, which compels employees to come early for work or stay additional hours. This concurred with the results of a study conducted by Ravinarayana \& Ramakrishna (2016), in which they discussed the impact of job stress on the effectiveness of the employees' performance. The study showed that job stress leads to more fatigue that affects overall performance. In addition to that, it found that the external factors involving physical environment, like job environment, relationships with people and dealing with problems, are all regarded as parts of the workload which impact on employee performance in organisations. In line with that, the current study agreed with the conclusions of a study conducted by CoxFuenzalida et al. (2006), where it was found that performance was significantly diminished for both conditions (sudden rise and downturn in workload situations). The findings indicated that either a sudden reduction (High to Medium) or increase (Low to Medium) in workload could result in declined performance. On the other hand, the current study did not concur with the results of a study carried out by Iwani (2015), which aimed to examine the impact of autonomy, workload, and work-life balance on job performance among teachers, the results of which revealed that workload had no substantial effect on employee performance among school teachers. At the same time, our current study also did not agree with the findings of a study conducted by Omolayo and Omole (2013) which examined the impact of mental workload on the job performance of academic and non-academic workers, as the result indicated that there is no significant relationship between mental workload and job performance.

With regards to the administrative participants of the current study and evaluation of their performance, the result found that the employees at KAU have evaluated their productivity on the job at a high rate, while at the same time also rating the quality of their performance highly. This positive evaluation of productivity and quality of performance was related to the availability of certain organisational factors. The results of this current study are in agreement with the results of a study conducted by Pawirosumarto et al. (2017) which found that there is a definite and essential influence, 
partially between leadership style, employee motivation and discipline, on employee performance. In line with that, the results of the current study also agreed with the results of a study conducted by Purbasari \& Septian (2017) -findings make it clear that compensation and positive work environment have an effect on employee performance. In line with that, regarding the factors that influence employee performance and the factors that associated with the improvement of employee performance, our current study results also agreed with the results of the study conducted by Hakami Nasab et al. (2014), which found that there is a positive correlation and meaningful relationship between employee performance and TQM components.

Based on the conclusions derived by the current study, it can be stated that the supervisor has a dual role in serving the employees and the organisation through practicing effective leadership, in addition to employees believing that they have complete trust in their supervisor's inspirational motivation, thus providing help for employees to find meaning in their work. In spite of these positive indications of the supervisor's role, the study showed that not all employees at KAU support the role of supervisors in the university, so there is a need to study such issues in order to arrive at the main causes of the low assessment of supervisors by some of the administrative employees. In addition to that, our current study, with regards to the impact of transformational leadership on administrator's performance in KAU, has concluded that there is a significant positive correlation between transformational leadership and employee performance. Additionally, the results revealed that transformational leadership has impacted the staff performance significantly. Therefore, these results are in line with various studies conducted on this topic, such as a notable study conducted by Psychogios and Garev (2012), which concluded that there is a relationship between employees and leaders which has positive effects on work outcomes, behaviours, and employee attitudes when clarity exists. Furthermore, the results of our current study also matched with those reported by Qazi et al. (2014), employee performance is significantly associated with the practice of leadership style and, in particular, the transformational leadership style. In line with that, Jiang et al. (2017) reached the same conclusion, that employee performance is positively influenced by the practice of transformational leadership. Furthermore, our current research is also in agreement with the findings of a study conducted by Sellers (2017), which proved that managers can improve employee performance by using the transformational leadership approach and indicated that there are many concepts, such as employee encouragement, managerial experience and adaptation, which are important when trying to improve employee performance.

\section{Conclusion}

There were some limitations identified in this study. One of the limitations noted was the small sample size. The small participant sample means the results are unable to be generalised to apply in all organisations. Further research must include a larger participant sample to ensure that better, more accurate information will be analysed and disseminated. The other limitation of the study is the shortage of time to conduct interviews which could be strengthened in future studies. Finally, this study was conducted in the public sector but could apply in private sector also. The most important recommendation that the situation shows, as all indications have proved, is that training and development are among the key organisational factors for the success of the organisations. They have to concentrate on training their employees to improve their skills, which would have a positive effect on job performance, and thus achieve the organisation's and employee's objectives. Additionally, there is no doubt that supervisors play a significant role in leading the employees at $\mathrm{KAU}$, which suggests that there should be a programme to incentivise supervisors. This programme will make organisations more equipped to lead the employees and provide them with necessary guides to achieve the best quality in their performance. The main objective of this study was the examination of the influence of some of the organisational factors on employee performance at KAU. The organisational factors that are expected to have significant influence on employee performance include training and development, workload and transformational leadership. The study was conducted on the administrators at KAU, concluding with various findings that might contribute to the improvement of the performance of administrative employees. It was found that training is considered to be one of the main factors that has a positive influence on employee performance, although the study revealed that there is no specific schedule for training program at KAU. One of the interesting findings in this study is concerned with the role of the supervisor at KAU, which revealed that the supervisor has a dual role in leading a group in work and meeting their needs, as well as organisational requirements. However, the study found that there are some employees who were not satisfied with the supervisor role. Therefore, there is a need to review the situation carefully to find solutions. Furthermore, the study revealed that most administrative employees feel that they carry out much work, which compels them to come to work early, or stay after hours. Therefore, the study provides various recommendations to settle such matters in the future.

\section{References}

i. Adair, J.m (2002). Effective strategic leadership. Macmillan Publishers Limited, London.

ii. Aggarwal, J., \& Krishnan, V. R. (2013). Impact of transformational leadership on follower's self-efficacy: Moderating role of follower's impression management. Management and Labour Studies, 38, 297-313. doi:10.1177/ 0258042X13513129

iii. Aguinis, H. and Kraiger, K., (2009). Benefits of training and development for individuals and teams, organizations, and society. Annual review of psychology, 60, pp.451-474.

iv. Anitha, R. and Kumar, M.A., (2016). A study on the impact of training on employee performance in private insurance sector, Coimbatore district. International Journal of Management Research and Reviews, 6(8), p.1079.

v. Anyango, C. A., (2015). Effects of Leadership Styles on Employee Performance at BOA Kenya Limited.

vi. Armstrong, M., (2009). Human Resource Management Practice. London: Kogan. Pages unlimited. 
vii. Atan, J.b., Raghavan, S. \& Mahmood, N.H.N. (2015). Impact of Training on Employees' Job Performance: A Case Study of Malaysian Small Medium Enterprise, Review of Management, vol. 5, no. 1, pp. 40,50.

viii. Basri, H.H., Rashid, I.M.A., Abashah, A.B. \&Samah, I.H.A., (2017). The impact of Malay transactional leadership style on employee performance; the Malaysia pharmacy industry perspective, International Journal of Information, Business and Management, vol. 9, no. 2, pp. 45-52.

ix. Bass, B. M. (1985). Leadership and performance beyond expectations. Free Press: New York.

x. Bass, B. M., (1990). Bass and Stogdill's handbook of leadership: Theory, research, and applications (3rd ed.). New York, NY: Free Press.

xi. Bass, B.M.; Riggio, R.E., (2006). Transformational Leadership; Psychol. Press: Hove, East Sussex, UK.

xii. Beardwell, I., Holden, L. \& Claydon, T., (2004). Human Resource Management a Contemporary Approach. 4th Ed. Harlow. Prentice Hall

xiii. Bushiri C., (2014). The Impact of Working Environment on Employees' Performance: The Case of Institute of Finance Management in Dar Es Salaam Region, University of Tanzania.

xiv. Campbell, J. P., R. J. Campbell, and Associates. (1988). Productivity in Organizations. San Francisco, CA: JosseyBass.

xv. Carvell, F. (1970). Human relations in business. Toronto: Macmillan Company.

xvi. Chanana M., Gupta S.K., (2016). Quality of Work Life and Its Impact on Job Performance: A Study of S.B.I \& HDFC Banking Professionals, International Research Journal of Engineering, IT \& Scientific Research, 3(5).

xvii. Chandra, T., \&Priyono, P. (2015). The influence of leadership styles, work environment and job satisfaction of employee performance-studies in the school of SMPN 10 Surabaya. International Education Studies, vol. 9, no. 1, pp. 131.

xviii. Cherry, K. (2012). How Transformational Leadership Inspire. Retrieved from http:// psychology.about.com/ od/ leadership/ a/ transformational.htm

xix. Church, A., Rotolo, C., Ginther, N., \& Levine, R. (2015). How are top companies designing and managing their highpotential programs? A follow-up talent management benchmark study. Consulting Psychology Journal: Practice and Research, 67(1), 17-47.

xx. Conchie, S. M. (2013). Transformational leadership, intrinsic motivation, and trust: A moderated-mediated model of workplace safety. Journal of Occupational Health Psychology, 18, 198-210. doi:10.1037/ a0031805

xxi. Cox Luz Eugenia, Fuenzalida, Beeler Cheryl, and Sohl Laura (2006), Workload History Effects: A Comparison of Sudden Increases and Decreases on Performance, Current Psychology, Social Spring 2006, Vol. 25, No. 01.

xxii. Cox-Fuenzalida, L.E. (2007). Effect of workload on task performance. Human Factors: The Journal of the Human Factors and Ergonomics Society 49, 277-291.

xxiii. Eze, F.C. (2005). Human resources management. Lecture note M. Sc/ Ph. D, Department of Business Management, 2005/ 2006 session, EBSU, Abakaliki, Nigeria.

xxiv. Gazette, S., (2016). Full text of Saudi Arabia's vision 2030. Saudi Gazette, 26.

xxv. Goldstein, I. I. (1974). Training: Program Development and Evaluation. Monterey, CA: Brooks/ Cole.

xxvi. Gordon, B. (1992). Are Canadian firms under investing in training? Canadian Business Economics 1,1, 25-33.

xxvii. Hakami Nasab, S., Hemmati, Y. \& Kia, S.H., (2014). An investigation on how TQM influences employee performance: A case study of banking industry, Management Science Letters, vol. 4, no. 1, pp. 31-36.

xxviii. Howell, J. M., \& Merenda, K. E., (1999). The Ties That Bind: The Impact of Leader-Member Exchange, Transformational and Transactional Leadership, and Distance on Predicting Follower Performance. Journal of Applied Psychology, 84(5), 680-694.

xxix. Ibrahim, R., Boerhannoeddin, A. \& Bakare, K.K., (2017). The effect of soft skills and training methodology on employee performance, European Journal of Training and Development, 41, (4), pp. 388-406.

xxx. Iwani, Z., (2015). Autonomy, workload, work-life balance, and job performance among teachers (Doctoral dissertation, Universiti Utara Malaysia).

xxxi. Orlin, J.B. and Ahuja, R.K., (1992). New scaling algorithms for the assignment and minimum cycle mean problems. Mathematical Programming, 54, pp. 41-56.

xxxii. Jiang, W., Zhao, X. \& Ni, J., (2017). The Impact of Transformational Leadership on Employee Sustainable Performance: The Mediating Role of Organizational Citizenship Behavior, Sustainability, 9, (9), pp. 1567.

xxxiii. Jowah, L. E., (2013). Followership: The forgotten kingmaker for effective leadership. Journal of US - China Public Administration, 10(7), 708-719. Retrieved from http:// davidpublishing.org/journals info.asp?jId=599

xxxiv. Judge, T. A., \& Piccolo, R. F., (2004). Transformational and Transactional Leadership: A Meta-Analytic Test of Their Relative Validity.Journal of Applied Psychology, 89, 5, 755- 768

xxxv. Kagaari, J.R., Munene, J.C. and Ntayi, J.M., (2013). Agency relations and managed performance in public universities in Uganda. SA Journal of Industrial Psychology, 39(1), pp.01-10.

xxxvi. KENNY, J. and M. REID, (1986). Training Interventions, Institute of Personnel Management, London.

xxxvii. Khaliq, A., (2001). Corporate leadership and workplace motivation in Malaysia. International Journal of Commerce and Management, 11(1), 82-101. Retrieved from http:/ / www.emeraldinsight.com/ journal/ijcoma

xxxviii. Khan, S.M., (2016). Role of Work Environment on Need Satisfaction in Asias Largest Transport Public Sector Organisation the Indian Railways. Journal of Organisation and Human Behaviour, 5(4), p.56.

xxxix. Leedal, J.M. and Smith, A.F., (2005). Methodological approaches to anaesthetists' workload in the operating theatre. British journal of anaesthesia, 94(6), pp.702-709. 
xl. Madhruma, L. and S. Sheetal, (2009). Personal Growth, Training and Development, John Wiley and Sons, New York.

xli. Mathis, R. L. and Jackson, J. H., (2004). Human Resource Management (10th ed.), Thomson Learning: Singapore.

xlii. Matthews, G., Davies, D.R., Westerman, S.J., \& Stammer, R.B., (2008). Human performance: cognition, stress, and individual differences. New York: Psychology Press.

xliii. McEvoy, G. M., (1990). Public sector managers' reactions to appraisals by subordinates. Public Personnel Management.

xliv. Mohiuddin, Z.A., (2017). Influence of Leadership Style on Employees performance: Evidence from Literatures, Journal of Marketing and Management, 8, (1), pp. 18.

xlv. Ognjenović, K., (2015). On-the-Job Training and Human Resource Management: How to Improve Competitive Advantage of an Organization? Organizacija, 48, (1), pp. 57-70.

xlvi. Omolayo, O.B. and Omole, C.O., (2013). Influence of mental workload on job performance. International Journal of Humanities and Social Science, 3(15), pp.238-246.

xlvii. Paracha, M. U., Qamar, A., Mirza, A., Hassan, I., \& Waqas, H., (2012). Impact of leadership style (transformational \&transactional leadership) on employee performance \&mediating role of job satisfaction. Study of private school (educator) in Pakistan, Global Journal of Management and Business Research, 12, (4), pp. 54-65.

xlviii. Pattanayak, B., (2005). Human Resource Management. India: Prentice Hall India.

xlix. Pawirosumarto, S., Sarjana, P.K. and Muchtar, M., (2017). Factors affecting employee performance of PT. Kiyokuni Indonesia. International Journal of Law and Management, 59(4), pp.602-614.

l. Psychogios, A. G., \&Garev, S., (2012). Understanding complexity leadership behavior in SMEs: Lessons from a turbulent business environment. Emergence: Complexity \& Organization, 14(3), 1-22. Retrieved from http:/ / emergentpublications.

li. Purbasari, R.N. and Septian, T.A., (2017). Factors influencing on employee performance of production department on the manufacturing food industry in Indonesia. Polish Journal of Management Studies, 16.

lii. Qazi, T.F., Shafique, M. \& Ahmad, R., (2014). Unveiling Leadership-Employee Performance Links: Perspective of Young Employees, Pakistan Journal of Statistics and Operation Research,10, (4), pp. 467-473.

liii. Ramlall, S., (2008). Enhancing Employee Performance Through Positive Organizational Behavior. Journal of Applied Social Psychology, 36(6), pp.1580-1600.

liv. Ravinarayana, K.S. \& Ramakrishna, H., (2016). Impact of Job Stress on Employee's Performance: An Empirical Study, i-Manager's Journal of Management, 11, (1), pp. 6-11.

lv. Robbins, M., (2009), Management, New Jersey: Pearson Education Limited.

lvi. Robbins, S. P., (2006). Organizational behavior. PT Index, Jakarta: Gramedia Group.

lvii. Rowe, W. G., (2001). Creating Wealth in Organizations: The Role of Strategic Leadership. Academy of Management Executive, 15: 81-94

lviii. Sellers, L.C., (2017). Leadership Strategies and Employee Performance Within Small Business, ProQuest Dissertations Publishing.

lix. Shafie, B., Baghersalimi, S. and Barghi, V., (2013). The relationship between leadership style and employee performance. Singaporean journal of business economics and management studies, 2(5).

lx. Shah SSH, Jaffari AR, Aziz J, Ejaz W, Ul-Haq I, Raza SN., (2011). Workload and performance of employees. Interdisciplinary Journal of Contemporary Research in Business 3(5): 256-67

lxi. Swart, J., Mann, C., Brown, S. \& Price, A., (2005). Human Resource Development: Strategy and Tactics. Oxford. Elsevier Butterworth-Heinemann Publications.

lxii. Tolulope, A., (2016). Manpower training and employee performance in public organizations: A study of Ogun state property and investment corporation (OPIC). Revista de Administratie Publica siPoliticiSociale, 17, (2), pp. 17.

lxiii. Wall, T.D., Michie, J., Patterson, M., Wood, S.J., Sheehan, M., Clegg, C.W. and West, M., (2004). On the validity of subjective measures of company performance. Personnel psychology, 57(1), pp.95-118.

lxiv. Wright, P. \& Geroy, D. G., (2001). Changing the mindset: the training myth and the need for word-class performance. International Journal of Human Resource Management 12, (4), pp.586-600.

lxv. Yukl, G. (2006). Leadership in Organizations (6th ed.). New Jersey: Pearson-Prentice

lxvi. Zafar, Q., Ali, A., Hameed, T., Ilyas, T., \& Younas, H., (2015). The Influence of Job Stress on Employees Performance in Pakistan. American Journal of Social Science Research, 1, (4), pp. 221-225 